
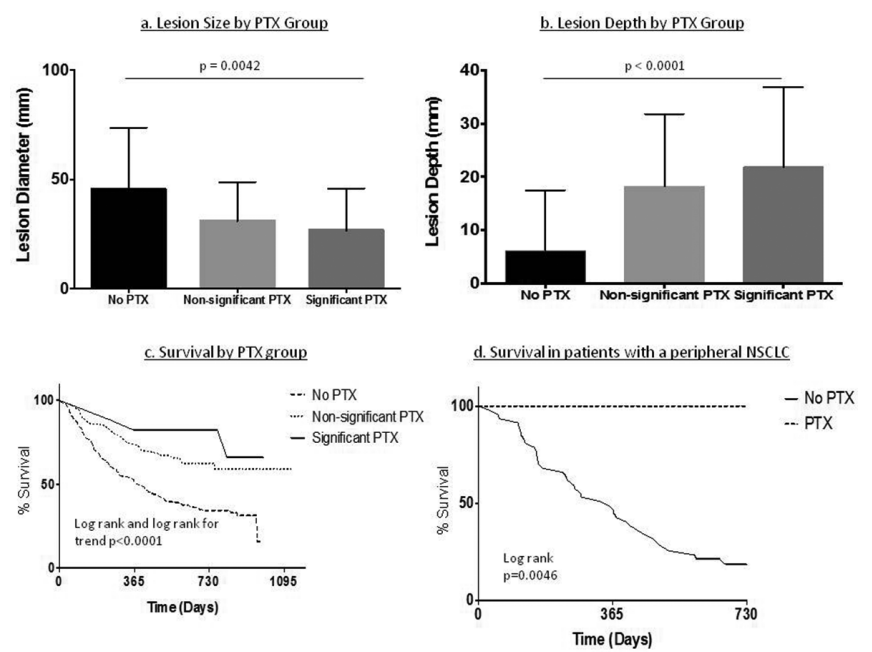

Abstract P222 Figure 1 (A) Lesion size by PTX group, (B) Lesion Depth by PTX group, (C) Survival by PTX group and (D) Survival in patients with a peripheral NSCLC

no deaths related to CTGLB (30-day mortality: 100\% in all groups).

SPTX were larger than nsPTX $(34( \pm 6) \mathrm{mm}$ vs. $19( \pm 6) \mathrm{mm}$, $\mathrm{p}=0.0003)$. Other factors associated with sPTX were lesion size and depth (see Figure $1(\mathrm{a}$ and $\mathrm{b})$ ), larger needle gauge $(\mathrm{p}<$ $0.0001)$, higher FEV1 $(p=0.01)$ and lower DLco $(p=0.049)$.

Length of stay $(\mathrm{LoS})$ was longer in sPTX $(5.8( \pm 5.9)$ days, $\mathrm{p}<$ $0.0001)$ and nsPTX $(1.7( \pm 2.3)$ days, $\mathrm{p}<0.0001)$ than No PTX $(0.7( \pm 0.9)$ days), but long-term survival was better (see Figure 1 (c and $d)$ ). This survival difference was pronounced in a subgroup of patients with a peripheral non-small cell lung cancer (defined as a lesion depth $\leq 0 \mathrm{~mm}, \mathrm{n}=53$ ).

Conclusions CTGLB was associated with a low rate of sPTX $(6 \%)$ and no short-term mortality. sPTX was associated with lung function indicative of emphysema and smaller, deeper lesions. The latter association likely explains the apparent survival advantage found in PTX patients but any long-term survival disadvantage seems unlikely. Post-CTLB PTX may be a positive sign in peripheral NSCLC, possibly inferring resectablilty.

\section{P223 CONSENT FOR MEDICAL THORACOSCOPY: THE TRUTH, THE WHOLE TRUTH AND NOTHING BUT THE TRUTH?}

SJ Jafri, K Ramsay, PA Beckett, RJ Berg. Royal Derby Hospital, Derby, UK

\subsection{6/thoraxjnl-2014-206260.352}

Introduction Failure to provide adequate information for valid informed consent may impact negatively on patient satisfaction and trust, and is a common cause of medical litigation. Some professional societies produce standardised consent forms in an attempt to reduce variation in quality of consent. There is no published national guideline standard for consent for medical thoracoscopy. We reviewed the quality of consents for medical thoracoscopy in a unit performing an average of 40 medical thoracoscopies per year.

Methods Case records of 80 patients who had undergone medical thoracoscopy were retrospectively reviewed. Consent forms were assessed for mention of potential complications, and grade and competency at thoracoscopy of consent-takers. We analysed the consistency between consents taken by the same individuals at different times, and numbers of patients experiencing complications for which they were not consented.

Results Consent was taken by 19 individuals. Consultant thoracoscopists took $54 \%$ of consents; non-thoracoscopist consultants took $15 \%$ and trainees $31 \%$. Potential complications consented for were: bleeding (100\%), 'infection' (99\%), persistent pneumothorax/trapped lung (81\%), pain (73\%), Empyema (46\%), damage to underlying organs $(28 \%)$, respiratory distress $(28 \%)$, nondiagnostic procedure (20\%), (talc related) fever (16\%), cardiac complications (15\%) and haemothorax (10\%).

Consultant thoracoscopists were significantly more likely than all other consent-takers to consent patients for empyema; $72 \%$ vs $16 \%$ of consents, $\mathrm{p}<0.001$, and pain; $93 \%$ vs $49 \%, \mathrm{p}<$ 0.001 .

Consistency with which consent-takers omitted or mentioned complications varied by individual and complication. For example, those individuals who consented at least once for empyema (7/19 consent-takers) did so collectively on $80 \%$ of their consents (individual range 25\%-100\%), whereas those who took consent for damage to underlying organs (10/19 consent-takers) did so on only $35 \%$ of their consents (range 5\%-100\%).

Empyema occurred in $5 \%$ of patients, all of whom had been consented for this complication. $38 / 80$ patients (48\%) experienced significant pain, of whom $34 \%$ were not consented for this.

Conclusion Information provided on thoracoscopy consent forms is inconsistent, both for common minor and serious complications. Even experienced thoracoscopists may fail to clarify significant complications. Introduction of a standardised consent form could reduce variation and consequent potential for patient distress and medico-legal risk.

\section{P224 LYMPH NODE ASSESSMENT IN SURGICAL RESECTION OF NON-SMALL CELL LUNG CANCER (NSCLC): ARE WE HITTING THE TARGET?}

AC McKay, H Ewan, G Beattie, AJB Kirk, M Asif. Thoracic Surgery, Golden Jubilee National Hospital, Glasgow, UK

\subsection{6/thoraxjnl-2014-206260.353}

Introduction Guidelines from the British Thoracic Society (BTS) and the National Institute for Health and Care Excellence (NICE) recommend that nodal assessment be performed in all patients who have anatomical lung resection for NSCLC.

Nodal status is one of the major determinants of outcome and most multidisciplinary teams now record adequacy of nodal assessment. N1 nodes are removed with the specimen perforce; therefore, a better indicator of surgical performance is the number of N2 nodal stations sampled.

This paper describes a continual audit cycle of lymph node sampling performance data in relation to N2 nodes.

Methods A retrospective analysis of patients who underwent anatomical lung resection for NSCLC in the calendar years 2009, 2010, 2012 and 2013 was undertaken. Lymph node sampling data was taken from pathology reports. The number of different stations sampled, rather than number of individual lymph nodes, was counted. Basic patient demographics were also collected.

After each audit cycle individual results were tracked and presented at open local, regional and national forums.

Results A total of 937 patients were audited after anatomic lung resection for NSCLC during the study periods. Pathology of NSCLC resections were as follows: 52\% adenocarcinoma, 
$33.9 \%$ squamous cell carcinoma, $7.3 \%$ large cell carcinoma, $6.1 \%$ other. The data is summarised in the table below:

Conclusion

- Audit over the past 3 years shown steady improvement in lymph node assessment performance.

- Continuous auditing and presentation of individual surgeon data at local, regional and national forums has contributed to the increasing compliance to the guideline targets

- There remains scope for further improvement and consultant engagement.

- Re-auditing will be essential to further improve compliance with guidelines.

\section{P225 REVISED BTS GUIDELINES FOR SECURING CANCER DIAGNOSIS AT BRONCHOSCOPY - A HIGHER RECOMMENDED YIELD IS REALISTIC AND ACHIEVABLE}

AE Stanton, CI Mackinlay. Department of Respiratory Medicine, Great Western Hospitals NHS Foundation Trust, Swindon, UK

10.1136/thoraxjnl-2014-206260.354

Introduction The recently updated BTS guidelines ${ }^{1}$ on bronchoscopy recommend that a diagnostic level of $85 \%$ should be attainable when definite endobronchial tumour is visible, an increase from previous recommendation of $80 \%$. We investigated whether this higher level was achievable.

Methods All patients undergoing bronchoscopy for suspected lung cancer were prospectively entered into a departmental database from April 2010, with performance analysed annually. The following specific data were entered: level of tumour presence (none seen / possible / definite tumour); diagnostic specimens taken (biopsy, brush, wash, TBNA); result of each diagnostic specimen (tumour present / not present, with reports "suspicious or suggestive" of tumour classified as "not present" unless there was a specific MDT decision to give a cancer diagnosis), and whether bronchoscopy was diagnostic of lung cancer overall. Finally clinical records were reviewed in patients without a bronchoscopic diagnosis of cancer to determine their final diagnosis. Results In the 4 full years since commencement of data collection, 356 bronchoscopies were performed for suspected lung cancer, with confirmed cancer diagnosis in 301. Table 1 summarises diagnostic sensitivity for endobronchial biopsy, brush, wash and overall sensitivity for lung cancer diagnosis at bronchoscopy in patients with bronchoscopically definite tumour seen. In $3 / 4$ years our overall diagnostic sensitivity has reached the level recommended (86.4-91.7\%), with first year performance just below the new standard (84.4\%).

Conclusions The revised level of recommended diagnostic rate at bronchoscopy for definite tumour appears to be realistic and achievable. This should remain as the standard of care for patients undergoing bronchoscopy for suspected lung cancer.
REFERENCE

BTS Guideline for diagnostic flexible bronchoscopy in adults. Thorax 2013;68(Suppl 1)

P226 WITHDRAWN

\section{Asthma treatments}

\section{P227 EFFICACY AND SAFETY OF BUDESONIDE-FORMOTEROL (BF) SPIROMAX® IN ADULTS AND ADOLESCENTS WITH ASTHMA: RANDOMISED COMPARISON WITH BF TURBUHALER $®$}

${ }^{1} \mathrm{JC}$ Virchow, ${ }^{2} \mathrm{G}$ Gopalan, ${ }^{3} \mathrm{R}$ Rodriguez-Roisin, ${ }^{2} Y$ Shu. ${ }^{1}$ University Hospital Rostock, Rostock, Germany; ${ }^{2}$ Teva Pharmaceuticals, West Chester, USA; ${ }^{3}$ Universitat de Barcelona Villarroel, Barcelona, Spain

\subsection{6/thoraxjnl-2014-206260.355}

Background DuoResp Spiromax ${ }^{\circledR}$ (Teva Pharmaceuticals) is a dry-powder inhaler designed to deliver budesonide and formoterol fumarate (BF Spiromax ${ }^{\circledR}$ ) with maximum ease of use. Pharmacokinetic studies have shown bioequivalence of $\mathrm{BF}$ Turbuhaler $^{\circledR}$. This study compared the efficacy and safety of these devices in patients with asthma.

Methods This was a 12-week, multicentre, double-blind, randomised, controlled trial $(\mathrm{N}=605)$. Eligible patients $(\geq 12$ years old) had persistent asthma with $\mathrm{FEV}_{1} 40-85 \%$ predicted, had used a SABA and ICS for $\geq 8$ weeks before screening and were maintained on stable-dose ICS for 4 weeks. The primary objective was to demonstrate non-inferiority of twice-daily BF Spiromax ${ }^{\circledR} 160 /$ $4.5 \mathrm{mcg}$ to BF Turbuhaler ${ }^{\circledR} 200 / 6 \mathrm{mcg}$, with respect to change from baseline in weekly average of daily trough morning PEF.

Results This analysis was based on the per protocol population $\left(\mathrm{N}=290\right.$ and $\mathrm{N}=284$ for BF Spiromax ${ }^{\circledR}$ and BF Turbuhaler ${ }^{\circledR}$ groups, respectively). The least squares mean change from baseline to Week 12 in morning PEF was $18.8 \mathrm{~L} / \mathrm{min}$ with BF Spi$\operatorname{romax}^{\circledR}$ and $21.796 \mathrm{~L} / \mathrm{min}$ with BF Turbuhaler ${ }^{\circledR}$. Noninferiority of BF Spiromax ${ }^{\circledR}$ vs BF Turbuhaler $^{\circledR}$ was demonstrated, as the lower limit of the $95 \%$ two-sided CI $(-9.02 \mathrm{~L} /$ $\min$ ) is greater than $-15 \mathrm{~L} / \mathrm{min}$. Similarly, no significant between-group differences were observed in secondary efficacy endpoints. Both devices were well tolerated, with no significant differences in the incidence of adverse events or asthma exacerbations.

Conclusions This study has demonstrated the non-inferiority of BF Spiromax ${ }^{\circledR}$ vs BF Turbuhaler $^{\circledR}$ in adults and adolescents with asthma. Further data are required to confirm whether BF Spiromax ${ }^{\circledR}$ can be used as an alternative to BF Turbuhaler ${ }^{\circledR}$ in other indications. Sponsor: Teva Pharmaceuticals.

\begin{tabular}{|c|c|c|c|c|c|c|c|}
\hline Year & $\begin{array}{l}\text { No. of Bronchs - } \\
\text { Suspected LC }\end{array}$ & $\begin{array}{l}\text { No. with } \\
\text { confirmed LC }\end{array}$ & $\begin{array}{l}\text { No. of bronchs - } \\
\text { definite tumour seen }\end{array}$ & $\begin{array}{l}\text { Biopsy } \\
\text { sensitivity (\%) }\end{array}$ & $\begin{array}{l}\text { Brushing sensitivity } \\
(\%)\end{array}$ & $\begin{array}{l}\text { Washing sensitivity } \\
(\%)\end{array}$ & $\begin{array}{l}\text { Overall sensitivity when } \\
\text { definite tumour seen }(\%)\end{array}$ \\
\hline 2010-11 & 92 & 72 & 33 & 67.7 & 66.7 & 43.8 & 84.4 \\
\hline 2011-12 & 87 & 71 & 41 & 80.6 & 60.7 & 27.8 & 86.4 \\
\hline 2012-13 & 90 & 81 & 52 & 81.3 & 55.8 & 30.6 & 86.5 \\
\hline 2013-14 & 87 & 77 & 36 & 80 & 71.4 & 47.2 & 91.7 \\
\hline
\end{tabular}

